\title{
Exploring Clinical Supervision Model employed by Qualified Nursing Staff at Mbarara Regional Referral Hospital and its Contribution to Students' Competencies.
}

\author{
Mark Opio a,1 \\ ${ }^{\text {a }}$ Faculty of Medicine, Department of Nursing, Mbarara University of Science and Technology
}

Abstract

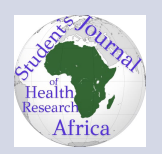

Background. ${ }^{a}$

Clinical supervision is an instructional face-to-face interaction between the supervisor and the supervisee which enables the supervisee to perform his/her job better. There is a various model which is being used in the supervision of students which includes coaching, mentorship, preceptorships, and individualized model when used leads to the acquisition of knowledge, skills, improve performance and students competencies. The purpose of the study was to explore clinical supervision models employed by qualified nursing staff at MRRH and their contribution to students' competencies

Methodology.

A qualitative descriptive design was employed in this study. The purposive sampling method was used to recruit 9 participants. Data collection was done by in-depth interview method using a semi-structured interview guide. Inductive content analysis was used to generate the themes and categories.

Results.

The study findings revealed three themes that emerged as the participants' descriptions of the clinical supervision model. These themes included coaching, self-directed learning, and individualized learning.

Conclusion and Recommendation.

The supervisory model used by the qualified staff in this study was coaching; mentoring, self-directed learning that enhances professional growth and skills competencies as well as promoting the relationship between the supervisor and the supervisee. The use of supervisory models in clinical practice should be emphasized so that nurse practitioners use them to provide the best learning to approach that enables students to achieve competencies. Integration of supervisory models in the nurse curriculum so that they know the importance of when they qualify and utilize them during the supervision of students to maximized learning in a clinical setting.

${ }^{a}$ submitted: 24th/06/2021 ac-
cepted: 26th/06/2021 email: opi-
omark44@gmail.com

\section{Background of the study:}

Clinical supervision is an instructional face-to-face interaction between the supervisor and the supervisee which enables the supervisee to perform his/her job better (ABIDDIN, 1980). It has been found that this approach improves growth and skills in a given profession while promoting a relationship between the supervisor and the super- 
visee(ABIDDIN, 1980). The supervision model is regarded as a conceptual framework that can assist in the delivery of clinical supervision (Mullarkey, 2000). The supervision models guide the practice with specific clarity. Otherwise, nurses might be at loss as to what they offer as they engage in supervision (Mullarkey, 2000). In addition, clinical supervision strengthens the clinical education environment because the clinical supervisors mentor and directly oversee nursing students(Gabieba et al., 2018).

A number of models are being used, however, individual clinical models are preferred especially in nursing(Kendrick, 1999). Currently, Nursing students' clinical abilities are highly dependent on the quality of the clinical experience obtained while placed in the clinical environment. It has been noted that knowledge on the use of the appropriate model for clinical supervision may be associated with better clinical competence among the students (Magerman, 2015). When the clinical supervision model is used, supervisors are able to be more effective when delivering the supervisory role(KemalKaylkcl1, 2017). Despite the known benefit and the various clinical supervision models used there is a dearth of information in the study area of the supervision models used by the clinical supervisors. This study, therefore, sought to explore what clinical supervision model nurses at Mbarara Regional Referral Hospital use while supervising students in the clinical setting.

Globally numerous clinical supervision models were being used with the individual clinical model of supervision becoming preferred in state of practice and examination (Watkins, 2012; Wiley, 2014). Also, they were being considered essential to the development of nurses' competencies (Watkins, 2012; Wiley, 2014). David et al., (2017) in their study "Does clinical supervision of healthcare professionals improve the effectiveness of care and patient experience? A systematic review" conducted in Australia, noted that reflective model of clinical supervision is used in the supervision of health professionals, and was associated with improvement of performance and effectiveness of care. However, little was known about the effect of clinical supervision in nursing in the study area. A study by Jette Elsborg Foss, (2014) on a Clinical Model-Based Practice (CMBP)for collaboration between university college and nursing practice to promote research utilization in students clinical placement: a pilot study found that the student's nurses performance and quality care to patients improved. However, the model had challenges in the implementation, and they recommended it be refined.

Magerman, (2015) study revealed that clinical supervision models like mentorship, coaching, preceptorships were being used during the supervision of undergraduate nursing students in their clinical education environment, in the Western Cape Town of South Africa. These models were to ensure that the supervisors perform their tasks. The main challenge noted during the supervision was how best to select appropriate clinical supervision model and their use to support students (Magerman, 2015).

In Uganda, a study by Mubeezi, (2016) revealed that clinical supervision models like mentorship; coaching, and expert models were being used to improve the student nurses' competencies. However, she noted that the use of these models was still low among nursing staff (Mubeezi, 2016). Although the use of clinical supervision models and their contributions were sighted in many areas, not much was known in the study area. The above gap prompted the researcher to explore the use of clinical supervision model by the staff of MRRH and identify the contributions to students' competencies.

Student nurses placed on the ward for clinical practice are supposed to be supervised by qualified nursing staff (Public Service of Uganda, 2017). Nursing students' clinical abilities were highly dependent on the quality of the clinical experience obtained while placed in the clinical environment (Magerman, 2015). The use of the appropriate model for clinical supervision was associated with better clinical competence among the students. A student who has been supervised by the staff who used models of clinical supervision like mentorship, perspective, and coaching; was able to improve their performance during practice (Mahere, 2000). Research indicates that health staff was not certain about the clinical supervision model and how to use them (Davenport, 2013). In addition, during the researcher's clinical practice on different wards at Mbarara Regional Referral Hospital (MRRH) from August 2018 to September 2019; he noted that it was not clear which clinical supervision model the qualified staff were using to supervise the students. There was a paucity of information regarding the clinical supervision model and its contribution to 
students' competencies. These gaps justified the need for this study to explore the model of clinical supervision employed by the qualified nursing staff at MRRH while supervising students.

\section{Purpose of the study}

To explore clinical supervision models employed by qualified nursing staff at MRRH and their contribution to students' competencies

\section{Research question}

What clinical supervision models are employed by the qualified nurses at MRRH in supervising the nursing students to enable them to acquire clinical competencies?

\section{Conceptual Framework:}

This study was guided by a proctor functional interactive model. According to Sloan (2002), the proctor functional interactive model explained how skilled supervisors and supervisee are brought together in a process of professional support and learning. Supervisors can help the supervisee to reflect on their practice in order to enable the supervision process. He noted that this model is most commonly used and it has three constructs which described the task and responsibilities of supervisors and supervisee, these included normative, formative, and restorative.

\section{Formative}

The supervisor looks at the challenge of not using the clinical model during the supervision yet it is a requirement in their job description; they relate it to knowledge gap, motivation, Clinical Supervision structure. Despite all these, they end up providing supervision to students. The action that is performed is to promote skills development, increase knowledge and improve the attitude of the supervisor and supervisee.

\section{Normative}

This means that supervisors should be conversant with managerial issues and clinical aspects while maintaining professional standards, this helps them to weigh the effectiveness of the clinical supervision model when providing supervision to students. This is also associated with the workload, role conflict, limited time, and limited objectivity of mentee (Mubeezi, 2016)

\section{Restorative:}

The supervisor looked at himself/herself as being unable to provide a supervisory role to nursing students. They (Supervisors) engage the students in performing an activity while they observed them do it. These focus on reducing stress-induced on the student while doing the work of nursing at a time when they are left alone during their clinical ward placement.Figure 1: Proctor's Functional Interactive Model

\section{Study Methods \\ Study area}

This study was conducted at Mbarara Regional referral Hospital (MRRH). The hospital is in Mbarara municipality, Mbarara district in western Uganda. It is located $1.5 \mathrm{~km}$ from Mbarara city center along Kabale highway, approximately $266 \mathrm{~km}$ from Kampala capital city of Uganda. Being a Regional Referral Hospital it serves the district of Isingiro, kiruhura, Ibanda, Bushenyi, Ntugamo, Mitoma Sheema, Buhweju, Lyatonde, Mbarara, Rwampara, and Rubirizi (MOH 2010). The hospital had an estimated bed capacity of 350 (MRRH Annual report, 2018). The study area was chosen because it is a teaching hospital where all the student nurses were placed during their clinical practice (training) and supervised by qualified nurses. It was also easier to be accessed by the researcher, less costly in terms of transport and there was enough time to carry out the research given that the researcher was a student at MUST.

\section{Study design}

A descriptive qualitative study design was used. The study design was chosen because it enabled the researcher to discover and understand the process (practice) in clinical supervision (Carmel, 2017, VA Lambert, 2012)

\section{Study population}

The study participant included qualified nursing staff on the wards of MRRH who supervise students as required by their job description and was willing to participate. They were chosen because of their interaction with student nurses and were capable of giving in-depth information on the clinical supervision model.

\section{Sampling method}

A purposive sampling method was employed in the selection of qualified nursing staff that supervises nursing students and were suitable for the research study. This method was chosen because participant would give adequate in-depth information regarding the clinical supervision model (Taherdoost, 2016)

\section{Sample size}

The sample size involved 9 participants, however, this was determined when there was no new infor- 
mation was forthcoming or data redundancy (Polit and Beck, 2012).

\section{Inclusion criteria}

Qualified nurses and midwives (at the level of assistant nursing officer and above) working on medical, surgical, psychiatric, pediatric, $\mathrm{MCH}$, and maternity wards who consented were selected. This was because they had the information to the questions this study was exploring and they were directly involved in the supervision of the student nurses.

\section{Exclusion criteria}

Qualified nursing staff who were absent at the time of data collection.

\section{Access}

After obtaining an introductory letter from the Department of Nursing and FRC of MUST, authorization was soughed from the Hospital Director and Senior Principal Nursing Officer (SPNO) who introduced the researcher to the ward in charge of the selected different wards.

\section{Pilot study}

This was a small-scale study that was done with the aim of identifying if the important issues in the main study will be achieved (Cadete, 2017). This was done in a health facility where students go for practice. It was done before the main study to confirm that the data collection tools were suitable, understood, and addressed the research question. The interview guide was modified to address the research questions and also gave the researcher an opportunity to improve on the questioning technique before the main data collection.

\section{Data Collection Tools}

A pre-designed semi-structured interview guide that consisted of two parts for staff demographic characteristics, and interview questions were used. The tools gave participants room to express themselves as they narrated what supervisory model they use and also asked questions (Bennet, 2018).

\section{Data collection procedure}

After clearance by the Hospital Director; participants were recruited after giving them the information about the study and seeking their consent. Permission was soughed to use audio recording during the interview, Participants were explained that the interview would take between 30-45 minutes and the information obtained shall be kept confidential and only be accessed by the researcher. The interview involved semi-structured questioners administered face to face.

\section{Rigors of the study}

Trustworthiness of the data collected was ensured /guaranteed by the principles of credibility, transferability, dependability, and conformability.

Credibility: This was established so that the result of the research was believable. An interview guide was used to capture the information related to the study. The interview guide was pre-tested to check for credibility and the gaps identified with the questions were addressed. The interview guide engaged the participants and enabled them to describe how the processes of supervision occur.

Confirmability: This demonstrated that the data represented the participants' responses and not the researcher's point of view (Polit and Beck, 2012, p.492). It considered the similarity between the two or more constructs about the data. The responses were recorded and Codes used to ensure that data collected were not mixed in any way

Dependability: This was addressed by using a semi-structured interview guide to collect all important information from each participant.

Transferability: The researcher demonstrated the research study findings were applicable to other contexts with similar populations and states (Polit and Beck,2012). This was achieved by clearly defining the character of the participants, the study area and methods used for collecting data, how it reached redundancy, and the finding as well. The reader would make their own judgment if the findings apply to their setting

\section{Data analysis}

Data were analyzed using inductive content analysis. Data collected (both audio-recorded and researcher notes) was transcribed verbatim; the researcher read line by line and generated similar quotes, categories of paragraphs, phrases, and formulated themes (Bennet, 2018)

\section{Ethical consideration}

Approval to conduct the study was obtained from the Department of Nursing and the University -Faculty Research Committee (FRC). The introductory letter from the Nursing Department of MUST was taken to the study area and permission was obtained from the Hospital Director of MRRH who introduced the researcher to the various wards. The purpose of the study was explained to each participant. They were requested to consent prior to participation in the study. They were informed that the participation was voluntary and they were 
free to withdraw anytime they wish. This would not affect their relationship with the researcher. Participants were explained that the information that was obtained would be kept confidential, no names shall be used except codes, data collected would be kept under lock and key kept by the researcher.

\section{Dissemination of results}

The researcher will submit copies of the research report to the MUST library, Department of Nursing MUST, and MRRH. The finding will also be presented at both local and international conferences. Publication shall be made in a peer review nursing journal.

\section{RESULTS}

This chapter presents the research finding of the participants' descriptions. Data were analyzed using content analysis. The findings are presented into three sub-sections namely; demographic characteristics of the participants, themes, and categories.

Socio-demographic characteristics of participants.

A total number of 9 participants were interviewed, their age ranged $35-44$ years and the mean age of the participants was 42.4 years. Most of the participants were females $75 \%$, males $25 \%$, their religion was as follows; $77.8 \%$ protestant, Roman Catholic $22.2 \%$. The participant's level of education, $66.7 \%$ had a diploma, bachelor level $22.2 \%$, and $11.1 \%$ reached a masters' level of education. Most of the participants interviewed (77.8\%) qualified between the year 2005 to 2019 and only $22.2 \%$ qualified between the year 2000 to 2004 . The participants had the varied title in the hospital.

\section{Participant's descriptions of a clinical super- vision model}

Four themes emerged as clinical supervision model and this included coaching, self-directed learning, mentorship, and individualized learning as shown in table 2 below.

\section{Theme 1: Coaching.}

The theme emerged from five categories which included teaching them slowly by slowly, continue teaching them. The staff also indicated that they consultation and demonstrate to students and they usually have staff student meeting during the rotation as indicated in the table 3 below.

\footnotetext{
Category 1: Teaching students slowly by slowly
}

Participants described that they teach students, give them tasks in a smaller portion, train students and observe them when they are performing the procedure. This was captured in the excerpts below;

"I first teach them what to do ... giving them a task in small portion....telling them slowly by slowly "(P8)

"......we train them on the particular procedure that we have in the ward and after you have trained someone a particular task then you start observing them do it; yeah" (P7, P9)

\section{Category 2: Continuous teaching}

Participants felt that the teaching has to be given repeatedly as they may fail to learn on day one. They also indicated that students forget and they have to continue and request the students to ask if they don't understand as noted in the statements below;

“........when you teach him/her today she fails ......tomorrow you again repeat, the other day you repeat like four times" (P8)

“... sometimes after showing them what to do they also forget and the next day you see the person is still messing up.... you don't stop at or in one day you continue until he/she is able to do it" ( P3)

"...... before we start work we put them down and we tell them that make sure whatever you don't know you have to ask from the staff" (P3)

\section{Category 3: Consultation}

Participants mentioned that they encouraged the students to continue consulting them as they work as they have time for them as stated below;

"I tell them whatever they are not sure of; they should come back and consult you as you also do other work because you cannot go supervise each and every student at a particular point in times",( P2)

"......we talk to students if you don't know anything come and tells me so that we go through it because we don't really have time for all of them "(P 9)

\section{Category 4: Demonstration}

Participants stated that they show students what is done on each ward and they expect the students to repeat what they have demonstrated.

They supervise and correct them as they perform while being observed as noted in their excerpts below;

"...we show them what to do right from the time they reach in the hospital.... show them each and everything because they know nothing as a student" (P3) 
Table 1. showing the themes and categories

\begin{tabular}{ll}
\hline Themes & Category \\
Coaching & - Teach students slowly by slowly $\bullet$ Continuous teaching $\bullet$ Consultation $\bullet$ Demonstration \\
& - Staff -student meeting \\
Self-directed & $\bullet$ Tasks allocation $\bullet$ Orientation of students $\bullet$ Grouping students \\
learning & - Follow student objectives \\
Mentoring & - Students perform on their own \\
Individualized & \\
\hline learning &
\end{tabular}

Table 2. theme 1: Coaching

\begin{tabular}{ll}
\hline $\begin{array}{l}\text { Themes } \\
\text { Coaching }\end{array}$ & $\begin{array}{l}\text { Category } \\
\text { - Teach students slowly by slowly } \bullet \text { Continuous teaching } \bullet \text { Consultation } \bullet \text { Demonstration } \\
\text { - Staff-students meeting }\end{array}$ \\
$\begin{array}{l}\text { Self-directed } \\
\text { learning }\end{array}$ & - Tasks allocation $\bullet$ Orientation of students $\bullet$ Grouping students \\
$\begin{array}{l}\text { Mentoring } \\
\text { Individualized } \\
\text { learning }\end{array}$ & - Follow student objectives \\
\hline
\end{tabular}

".....I repeat for the student and tell him again to repeat "yeah"... let them also demonstrate after I have done" P2

"Of course I work with them..... Yes I give them chance to perform then I see where their weakness is then I try to correct them". (P6)

\section{Category 5: Staff -student meeting}

Participants indicated that they hold debriefing meetings at the beginning of students' clinical rotation. They claimed that they give feedback to students immediately or at some point in time as noted below;

"We always have a meeting at the end of the rotation day.... we sit as a staff of MCH and those students they give us their achievement and challenges met" (P5)

"For us here we give feedback meeting at the end of the procedure because we are few....we observe, we tell them after the procedure ...... you tell this student that here is done like this" (P9)

Theme 2 self-directed learning

This theme emerged from three categories namely; task allocation, orientation, and grouping students as indicated in table 4 below;

\section{Category 1: Task allocation}

A participant stated that they allocate tasks to students and after training them they observe them perform while they observe as indicated in their excerpts below;

"We try to allocate them task... we train them on the particular procedure that we have in the ward and after you have trained someone a particular task then you start observing them do it" ( P7.)

"...... you bring him by the bedside of the patient and ask him please can you do ..... Just show me what you have learned as you verbalize then for you verbalize afterward" (P1)

\section{Category 2: orientation of students}

Participants indicated that they take students around in areas where they perform procedures as claimed below;

"......when the students come, I orient them, I take them through areas where we have rooms..... areas of major procedure/activities in the ward and also orient them on what to do" (P5)

\section{Category 3: Grouping students}

Participants mentioned that when students come on the wards they are put in groups to enable them to be in smaller groups that are easier to supervise and enable them to learn better as stated below;

"Students come in big groups and we divide them so that each unit get a particular number of students 
Table 3. self-Directed learning

\begin{tabular}{ll}
\hline $\begin{array}{l}\text { Themes } \\
\text { Coaching }\end{array}$ & $\begin{array}{l}\text { Category } \\
\text { - Teach them slowly by slowly } \bullet \text { Continuous teaching } \bullet \text { Consultation } \bullet \text { Demonstration } ~ \\
\text { Staff- student meeting }\end{array}$ \\
$\begin{array}{l}\text { Self-directed } \\
\text { learning }\end{array}$ & $\bullet$ Tasks allocation $\bullet$ Orientation of students $\bullet$ Grouping students \\
$\begin{array}{l}\text { Mentoring } \\
\text { Individualized }\end{array}$ & $\bullet$ Follow student objectives \\
leaning & - Students perform care on their own \\
\hline
\end{tabular}

for a particular period so that they get exposed to different units and procedure" (P2)

"... I group them, I locate them/l distribute them according .... Where they want to work"( p5).

Theme 3: Mentoring

This theme emerged from one category following the students' objectives as indicated in table 4 below.

\section{Category 1: Follow student's objectives}

Participant claimed that they follow students' objectives to ensure that they are following the right teaching and goals as stated below;

"I ask them what their objectives are.... So that at the end of the rotation we see if the objectives are met", (p5)

".. We also ask them what they need from us so that we aimed at their goals when we are working with them ... if below standard, I tell her what she should do", (p6)

\section{Theme 4 individualized learning}

This theme emerged only one major category students performing care on their own as indicated in table 5 below;

\section{Category 1: students perform care on their} own.

Participants stated that they leave the students to do work on their own after some time and only to consult when they have too as noted below;

"...If they are these people who are been coming over and over then you can let them go do the work and then you instruct them to come and consult you where they are not sure" (P2)

\section{Discussion of the results}

The study employed 9 participants and their mean age was 42.4 years. Most of the participants were females $75 \%$ which indicates that it's a profession mostly practiced by females. This concurs with the study conducted in Uganda by Achora (2016) who found that nursing is predominantly a female profession, although the trend is changing nowadays.

Of the participant's level of education; $62.5 \%$ had a diploma. For effective transfer of knowledge and skills the supervisor should have attained a required level of education which helps him/her to supervise the supervisee while using the appropriate supervision model (coaching and mentorship). This is in line with a recommendation from the public service of Uganda (2017) which stipulates the role of qualified nursing staff in the Public Service of Uganda to provide coaching and mentorship to students and juniors should at least be at the level of the assistant nursing officer. Also, this finding concurs with a previous study of Warening (2018) who noted that when coaching is done by a qualified supervisor leads to improvement of performance.

Coaching The study noted that most participants were providing teaching, consultation, demonstration, and holding staff-student meeting during their clinical placement in the ward. Supervisor's support, and guidance to students through instructions during coaching helps the student to reflect practice/experience, focuses on skills, immediate improvement of performance, and prepare them to be more competent in handling procedures or ward activities. They demonstrate skills and their knowledge which contributes to patients' improved health as this is evaluated by a supporting relationship with the person receiving care. This finding concurs with a previous study of Warening (2018) who found out that when coaching is done regularly with a qualified supervisor leads to improvement of performance. Also finding from Paul Lawrence, (2014) indicated that when coaching is used students gain experience, self-awareness, and 
Table 4. showing the themes and categories

\begin{tabular}{ll}
\hline Themes & Category \\
Coaching & $\bullet$ Teach students slowly by slowly $\bullet$ Continuous teaching $\bullet$ Consultation $\bullet$ Demonstration \\
Self-directed & - Staff -student meeting \\
learning & \\
$\begin{array}{l}\text { Mentoring } \\
\text { Individualized }\end{array}$ & - Follow student objectives \\
learning & - Students perform on their own \\
\hline
\end{tabular}

Table 5. individualized learning

\begin{tabular}{ll}
\hline $\begin{array}{l}\text { Themes } \\
\text { Coaching }\end{array}$ & $\begin{array}{l}\text { Category } \\
\bullet \text { Teach them slowly by slowly } \bullet \text { Continue teaching them } \bullet \text { Consultation } \bullet \text { Demonstration } \bullet \\
\text { Staff student meeting during the rotation }\end{array}$ \\
$\begin{array}{l}\text { Self-directed } \\
\text { learning }\end{array}$ & $\bullet$ Tasks allocation $\bullet$ Orientation of students $\bullet$ Grouping students $\bullet$ Follow student objectives \\
$\begin{array}{l}\text { Individualized } \\
\text { learning }\end{array}$ & $\bullet$ Students perform care on their own \\
\hline
\end{tabular}

competency in handling patients which promotes their good health.

Finding from the study identified that regular staff-student meeting was used to assess the student performance and contribute to students competencies, this was majorly through feedback meeting which is held before, intermediately and after the students 'rotation in the unit. Coaching and mentorship which use feedback as providing information to learners are considered to transfer knowledge and skills to students; this leads to professional development. This study is in agreement with previous studies (Robinson, 2010, Abiddin, 2006) who found that the mentorship model of clinical supervision is considered as the most effective way to transfer knowledge and skill to a supervisee because it gives support, guidance and facilitate the mentee irrespective of their strengths and weakness, hence they acquire the competencies needed to practice as well as contributing to professional growth and development. This finding, therefore, answers the research question and objective of this study.

Self-directed learning Student learning ability is dependent on the task allocated basing on the set objectives which guide the student in practice. Expectations of the students are aligned with already designed objectives which are provided by the learners or the supervisor. In this study, the finding showed that the supervisor engages students in performing the activity while they observe them do it and this reduces wasting of time in implementation of the activity and reduces error, which leads to the acquisition of skills and knowledge. This agrees with the conceptual model

Individualized learning this study finding showed that the final year students are left alone to practice without being supervised, this makes students find a new strategy for learning which empowers them to attain mastery of skills and gain competencies, and take responsibility. This is not in line with the finding from Mousa Mahdizadheh, (2015) who showed that students' learning is dependent on the supervision of the student in order to achieve the competencies they need to practice. Also with finding from Underwood, (2019) indicated that effectiveness in patients cares depends on the quality of supervision offered by the qualified supervisor to student nurses. Students gain skills, knowledge, and leadership skills that can impact lives when providing service.

\section{Conclusion}

The study revealed four supervisory models used during the supervision of students in the clinical setting namely; coaching, self-directed learning, men- 
toring, and individualized learning to enhance professional growth and skills competencies.

\section{Limitation of the study}

Conducting the study during the covid19 period, participants were hesitant to the study but was overcome by adherence to SOPs guidelines.

The findings from the 9 participants interviewed cannot be generalized for all qualified nursing staff who supervise nursing students during their practice in the ward.

\section{The implication of the study}

Nursing: The study finding will enable the nurse managers and educators to emphasize the use of supervisory models while supervising the students during clinical placement.

Policy This research finding will contribute to ensuring that leaders adhere to the policy guidelines when providing supervision role to juniors/students

Research this will contribute to the new knowledge and provides areas for further researches

\section{Recommendations}

More information on the use of the clinical supervision model to the supervisor so that they are able to provide the best learning approach to students.

Integration of the teams, that is the hospital and the university in the supervision of students such that they can maximize learning in a clinical setting.

\section{Areas of future research}

There is a need to explore how student nurses perceive the model used by the qualified staff if it leads to acquiring competencies in clinical settings.

\section{Acknowledgment}

I would like to thank in a very special way my Heavenly Father for His grace towards me; without God, I wouldn't have achieved this.

I thank the administration of MUST and staff especially of Nursing Department for giving me all the support required for me to complete this research report.

I sincerely thank my supervisor, Dr. Nambozi Grace, for the maximum support and guidance rendered to me during this report production. May God bless you.

I would like also to appreciate the hospital administration of MRRH for allowing me to conduct the study in the hospital and also the participants for participating in the research.
I would like also to extend my appreciation to all the classmates who gave me support academically and materially.

Lastly, with great honor, I would like to thank my family members for the sacrifice of time, financial, social, and emotional support towards my research. May God bless you abundantly.

\section{LIST OF ABBERVERATIONS \\ CSM}

Clinical Supervision Model

MOH Ministry of Health

MRRH Mbarara Regional Referral Hospital

MUST Mbarara University of Science and Technology

PNO Principal Nursing Officer

REC Research Ethics Committee

SPNO Senior Principal Nursing Officer

\section{DEFINITION OF TERMS}

Clinical supervision model: is a tool that helps the mentor in the provision of supervisory role to a mentee

Competence: this is the ability of a student to practice according to the required standards in the nursing profession with little or minimal supervision

Mentors: are people who have adequate knowledge and skills in the provision of supervision to another person with limited knowledge and skills.

Mentee: is a person with limited knowledge and skills required to practice.

Qualified nursing staff: is a nurse who is registered, licensed, employed to practice nursing, and able to provide supervision to students as required by their job description

\section{References:}

1) Abiddin, D. Z. (1980). Exploring clinical supervison to facilitate the creative process of supervision. Uluslarasi SosyalArastirmalar Dergisi The journal of international social Research, 15.

2) Abiddin, D. Z. (2006). Mentoring and Coaching :The Roles and Practices. The journal of Human Resource and Adult Learning.

3) Achora, S. (2016).Conflicting image: Experience of male nurses in a Uganda's hospital, 1 https://doi. org/10.1016/j.ijans.2016.10.001

4) Bennet, D.(2018). How to analyse Qualitative data in diferent ways. The clinical teacher, 16(1),1. https://doi.org/10.1111/tct.12973

5) Cadete, L. (2017).Pilot studies can play a very important role prior to conducting a full-scale research project.Tutorials and fundamentals, 
6) Carmel Bradshaw, S. A,O.D (2017). Employing a ualitative Description Approach in Health Care Researc. SAGE journals. https://doi.org/10.1177/23 33393617742282

7) Davenport ,D. (2013, june). Nursing in practice. The basics of clinical supervison, 1

8) David, A.; Leggat,S.and Taylor, N. (2017). Does clinical supervision of healthcare professionals improve effectiveness of care and patient experience? A systematic review. BMC Health Services Research.

9) Gabieba, Donough \& Marianna(2018). Undergraduate nursing students' experience of clinical supervision. PMC, 41(1). https://doi.org/10.4102/c urationis.v41i1.1833

10) Jette Elsborg Foss, E. A. (2014). A model (CMBP)for collaberation between university college and nursing practice to promote research utilisation in students clinical placement:a pilot study. Nurse Education in practice.

11) Mullarkey, (2001). multiprofessional clinical supervision:challenges for mental health nurses. journal of psychiatric and mental health Nursing. $\mathrm{h}$ ttps://doi.org/10.1046/j.1365-2850.2001.00376.x

12) KemalKaylkcl1, O.Y, A. S (2017). The view of education supervisors on clinical supervision. Journal of education and practice.

13) Kendrick, D.(1999). clinical suppervision model for nursing:structure research and limitations. art and science management, 41.

14) Lambert, V. A., \& Lambert, C. E. (2012). Qualitative descriptive research:an acceptable design. international journal of nursing research, 16.

15) Magerman, J.(2015).Clinical supervisor experience of supervising nursing students from a higher education institution in the western cape. Aminithesis, 16.

16) Mahere S.M (2000). Clinical supervision model:Its Role in the professional Development of Teachers in Zimbabwe. Model of Clinical supervision in Education.

17) Mousa Mahdizadheh, A. H. (2015). Clinical interdisplinary collaboration models andframeworks from similarities to differences:asystematic Review. Global journal of health science. https://doi.org/10. 5539/gjhs.v7n6p170

18) Mubeezi, M. (2016). Mentoring student Nurses in Uganda:a phenomenological study of mentors perceptions of their own knowledge and skills. Nurses Education and Practice, 12,15. https:/ /doi.org/10.1016/j.nepr.2017.07.010
19) Paul Lawrence, A. W. (2014). what is coaching supervision and its important? Coaching :An international journal of theory, Research and practice. $\mathrm{h}$ ttps://doi.org/10.1080/17521882.2013.878370

20) Polit, D.F. and Beck, C.T. (2012).Essentials of nursing research; Appraising evidence of nursing care 7th edition. Philadelphia: Lippincott William and Wilkins, 492.

21) Public service of Uganda (2017). Schemes of service for the nursing and midwifery cadre, 46.

22) Robinson, J. (2010).Science of successful supervision and mentorship: model of clinical supervision, 3.

23) Underwood,S. J. G. (2019). evaluating the impact of coching pilot on students and staff. british jopurnal of nursing . https://doi.org/10.12968/bjon. 2019.28.21.1394

24) Taherdoost, H. (2016). sampling method in research methodology; how to chose a sampling technique for research. international journal of accedemic resrearch in management, 23. https://d oi.org/10.2139/ssrn.3205035

25) Watkins, E.C. (2012a). Defining and understanding clinical supervision: A functional approach. The Wiley International Handbook of Clinical Supervision.1-6

26) Wareing, H. G. (2018). journal of psychiatric and mental health nursing.

27) Wiley,J. (2014). Defining and understanding clinical supervision: A functional approach. The Wiley International Handbook of Clinical Supervision, 6 . 
Appendix I: Map of Uganda

showing the location of

Mbarara city in western Uganda

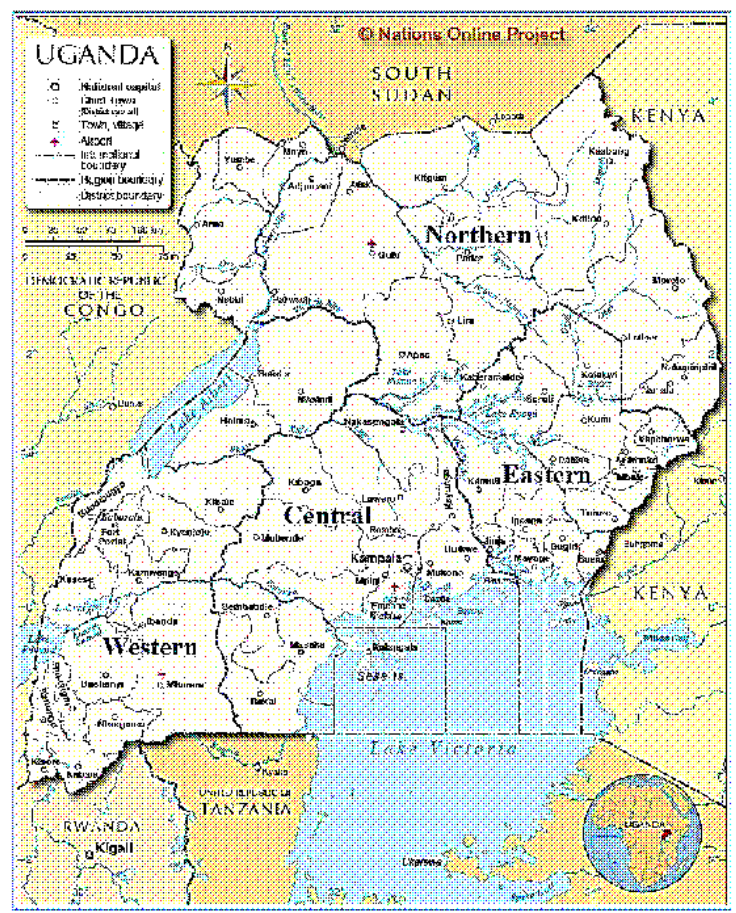

